\title{
Use of different approach in finding catch effort relationship in hook and line fishery in Kombuthurai village of Thoothukudi district of Tamil Nadu
}

\author{
A. Anuja \\ ICAR-Central Institute of Fisheries Education, Mumbai-400061(Maharastra), India \\ Vinod K. Yadav* \\ ICAR-Central Institute of Fisheries Education, Mumbai-400061(Maharastra), India \\ *Corresponding author. E-mail: vinodkumar@cife.edu.in
}

\section{Article Info}

DOI:10.31018/jans.v10i2.1756 Received: February 16, 2018

Revised: March 21, 2018

Accepted: April 22, 2018

\section{How to Cite}

Anuja, A. and Yadav, V.K (2018). Use of different approach in finding catch effort relationship in hook and line fishery in Kombuthurai village of Thoothukudi district of Tamil Nadu. Journal of Applied and Natural Science, 10(2): 648 - 654 used in GLMs. The variables that were found to be significant in both of the models distributions are year and season. GLM model was good fit with $\mathrm{R}^{2}$ ranging from $67.60 \%$ to a high of $91.7 \%$. The low and high abundance of CPUE were categorized taking the below and above average CPUE. A binary logistic regression model was used between the CPUE abundance and with above mentioned independent variables. The binary logistic regression model explained $75.4 \%$ (Nagelkerke $\mathrm{R}^{2}$ ) of the variance in high CPUE abundance and correctly classified $88 \%$ of cases. The independent variable such as latitude, longitude, depth, and distance added significantly to the model, but the year, season and hooks did not add significantly to the model.

Keywords: Binary logistic regression, CPUE, General Linear Model (GLM), Generalized Linear Model (GLMs), Hooks and line fishery

\section{INTRODUCTION}

Fisheries are a source of employment, income, nutrition, and recreation in the world. The continuing depletion of the world's marine fisheries resources is a key indicator of the critical decline in ocean health (Anuja et al., 2018). Moreover, fisheries have been pointed out as one of the five critical global systems according to the first world's ecological health assessment "the Millennium Ecosystem Assessment" carried out by Food and Agriculture Organization (FAO) in 2005. Responsible and sustainable fishing methods are the global needs of the time to save the fast depleting resources.

Kombuthurai is a small coastal village situated in the Coromandel Coast area of Thoothukudi district in Tamil Nadu. There are 195 fishermen households actively engaged in fishing (GOT, 2012). The traditional fishing village of migrant fishers from Kadiyapattinam formed a new village 35 years ago who follow simple, eco-friendly, eco- nomical fishing methods. The village has $110 \mathrm{Fi}-$ bre-reinforced plastic (FRP) vessels.

The prime focus of this work is to understand, analyze and present the most eco-friendly fishing practices in Thoothukudi district of Tamil Nadu (Anuja et al., 2018). Therefore, Kombuthurai fishing village was purposively selected since the village is unique in its practice of hook and line fishing, one of the most eco-friendly fishing practices in the world (Anuja et al., 2018).

Given the above, the present paper is an attempt to bring out sustainability of the fishing technique employed and the catch and effort relationship obtained through CPUE using GLM and GLMs and binary logistic regression models.

\section{MATERIALS AND METHODS}

The data was collected from Kombuthurai fishing village, Thoothukudi district, Tamil Nadu. Predesigned survey schedule was prepared for conducting the survey. Questions sought details information on vessel types, length of the vessel, ton- 
nage, fishing gear, crew size, annual fishing days, fishing duration, fishing distance from the shore, life of craft and gear, type of hooks, type of bait and fish catch according to season. Secondary data were collected from fishers associations on month and year wise fish landings.

Catch and effort time series data of hook and line fishery from 2009-2013 were taken from fishers associations on the month and year wise fish landings in Kombuthurai fishing village. The catch data is in weight in tons $(t)$ and effort taken in the form of number of fishing days and the time (hrs) spent in the hook and line fishing.

General linear models (GLM): General linear models (GLM) are the most common method used to standardize catch per unit effort (CPUE) (Allen, R. and Punsly, R., 1984). The CPUE is predicted as a linear combination of the explanatory variables. The year and season effect were used to represent the annual and seasonal relative levels of abundance and used as the relative index of abundance for stock assessment. The year and season effect were included in the GLM as a categorical variable.

GLM model was used to standardize CPUE concerning continuous and categorical predictor variables. In this study GLM model was used for the annual series with the year, month, season, and gear (hooks) as the fixed factor and latitude, longitude, depth and distance as covariates and the model was built.

LogCPUE $=\beta_{0}+\beta_{1} X_{1}+\beta_{2} X_{2}+\beta_{3} X_{3}+\beta_{4} X_{4}+\beta_{5} X_{5}+\beta_{6} X_{6}+\beta_{7} X_{7}+\varepsilon$

Where,

$$
\begin{aligned}
& \beta_{\mathrm{i}}=\text { Regressioncoefficients }, \quad X_{1}=\text { Year } \\
& X_{2}=\text { Season }, X_{\mathrm{a}}=\text { Hooks }, X_{4}=\text { Latitude } \\
& X_{5}=\text { Longitude }, X_{6}=\text { Depth }, X_{7}=\text { Distance } \\
& \text { and }^{\varepsilon}=\text { Error }
\end{aligned}
$$

Generalized Linear Model (GLMs): GLMs are defined by the statistical distribution of the response variable and how some linear combination of a set of explanatory variables relates to the expected value of the response variable (Maunder, M.N., and Punt, A.E., 2004). GLMs are the most common method for standardizing catch and effort data (Nelder et al.,1972). Gavaris (1980) appears to have been the first to have used a GLM approach to standardizing catch and effort data.

$$
G(E(Y))=\alpha+\sum_{k=1}^{k} \beta_{k x_{1 E}}
$$

Where, $G(E(Y))$ is some function of the expected value of Y

$\mathrm{Y} \sim \mathrm{F}$ (i.e. $\mathrm{Y}$ has some sort of distribution, e.g. normal, binomial, logistic, etc.)
$G$ is referred to as the link function, while $F$ is the distributional family

Binary logistic regression: The low and high abundance of CPUE were categorized taking the below and above average CPUE. A binary logistic regression model was developed between the CPUE abundance and with seven independent variables (continuous and categorical): latitude, longitude, distance, depth, seasons, years and fishing gear type. The probability of high or low abundance CPUE ( $p$ ) has been written in the equation below.

$$
p=\frac{1}{1+e^{-x}}
$$

Where, $z=\beta_{0}+\beta_{1} x_{1}+\beta_{2} x_{2}+\beta_{3} x_{3}+\beta_{4} x_{4}+\beta_{5} x_{5}+$ $\beta_{6} x_{6+} \beta_{7} x_{7}$

In which $\beta_{0}$ and $\beta_{i(i=1 \text { to } 7)}$ are the regression constants and $x_{i}(i=1$ to 7$)$ are seven independent variables

Where,

$$
\begin{aligned}
& \beta_{\mathrm{i}}=\text { Regressioncoefficients }, X_{1}=\text { Year }, \\
& X_{2}=\text { Season }, X_{\mathrm{a}}=\text { Hooks }, X_{4}=\text { Latitude } \\
& X_{5}=\text { Longitude }, X_{6}=\text { Depth }, X_{7}=\text { Distance } \\
& \text { and } \varepsilon=\text { Error }
\end{aligned}
$$

To assess the misclassification rate, we considered predicted $Y$ as 1 when $p \geq 0.5$ and 0 when $p$ $<0.5$. The model was fitted using a maximum likelihood method. Forward Wald step method was to select the significant variables in the final model. The $p$-value for statistical testing of variable significance for inclusion in and exclusion from the model is generally set to 0.05 .

\section{RESULTS AND DISCUSSION}

Kombuthurai has been described as a fishing village in Thoothukudi district, Tamil Nadu which has gained immense importance by practicing sustainable fishing practices.

Table 1 gives the catch, effort and catch per unit effort (CPUE) of Kombuthurai during 2009-2013. It

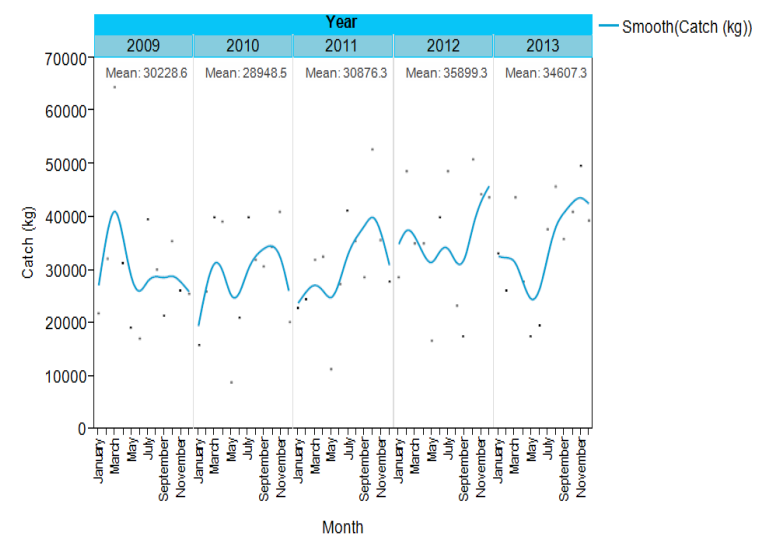

Fig. 1. Fish landings in Kombuthurai (2009-2013). 
Table 1. Catch, effort and CPUE of Kombuthurai fishers (2009-2013).

\begin{tabular}{llll}
\hline Year & Catch(kg) & Effort(hrs) & CPUE(kg/hr) \\
\hline 2009 & 362743 & 1720 & 210.89 \\
2010 & 347382 & 1709 & 203.27 \\
2011 & 366146 & 1643 & 222.85 \\
2012 & 430792 & 1708 & 252.22 \\
2013 & 415288 & 1598 & 259.88 \\
\hline
\end{tabular}

(Source: Fishers associations Kombuthurai, 2013)

Table 2. Levene's test of equality of error variances (2009-2013). (Dependent Variable log_cpue).

\begin{tabular}{cccc}
\hline $\mathbf{F}$ & df1 & df2 & Sig. \\
\hline 1.770 & 29 & 70 & .057 \\
\hline
\end{tabular}

Tests the null hypothesis that the error variance of the dependent variable is equal across groups.

can be seen from the table that the CPUE has varied from 0.20 tons to the maximum of 0.25 tons during the period of time. It is interesting to know that despite the range of effort varied from 1598 hrs to $1720 \mathrm{hrs}$. The catch has remained in the range of 347.4 tons to a maximum of 430.8 tons. This indicates a relationship between their fishing practice of using hooks and lines and relative consistency in catch.

Fig. 1 gives the month wise fish landings in Kombuthurai during 2009-2013. The mean fish landings ranged from 28.95 tons in 2010 to 35.90 tons in 2012. Even though the smooth curve of each year does not matched on a year to year basis the mean values of fish landings in Kombuthurai indicate relative consistence.

The seasonal landings of fish in Kombuthurai are divided into four seasons with a first season February to April; second season May to August; third season September to October and fourth season November to January. This is as per the seasonal calendar followed by the Kombuthurai fishers based on their experience. The first season February to April is identified as best for carangids fishery, the second season for tuna and seer fishes, the third for seer fish, carangids and cuttle fishes and the fourth exclusively for seer fishery.

Table 3. Factors influencing CPUE (2009-2013).(Dependent Variable log_cpue).

\begin{tabular}{lcccccc}
\hline Source & $\begin{array}{c}\text { Type III Sum of } \\
\text { Squares }\end{array}$ & df & Mean Square & F & Sig. & $\begin{array}{c}\text { Partial Eta } \\
\text { Squared }\end{array}$ \\
\hline Corrected Model & $8.013^{\mathrm{a}}$ & 12 & .668 & 19.010 & .000 & .724 \\
Intercept & .027 & 1 & .027 & .781 & .379 & .009 \\
Season & .901 & 3 & .300 & 8.546 & .000 & .228 \\
Major hooks & .039 & 1 & .039 & 1.123 & .292 & .013 \\
Year & 1.620 & 4 & .405 & 11.532 & .000 & .346 \\
Latitude & .004 & 1 & .004 & .101 & .751 & .001 \\
Longitude & .014 & 1 & .014 & .393 & .533 & .004 \\
Depth & .021 & 1 & .021 & .605 & .439 & .007 \\
Distance & .030 & 1 & .030 & .859 & .357 & .010 \\
Error & 3.056 & 87 & .035 & & & \\
Total & 2912.912 & 100 & & & & \\
Corrected Total & 11.069 & 99 & & & & \\
\multicolumn{7}{l}{ a. R Squared $=.724$ (Adjusted R Squared = .686) }
\end{tabular}

Table 4. Parameter estimates of the relationship CPUE and independent variable (2009-2013). (Dependent Variable: log_cpue)

\begin{tabular}{|c|c|c|c|c|c|c|c|}
\hline \multirow[t]{2}{*}{ Parameter } & \multirow[t]{2}{*}{ B } & \multirow[t]{2}{*}{ Std. Error } & \multirow[t]{2}{*}{$\mathbf{t}$} & \multirow[t]{2}{*}{ Sig. } & \multicolumn{2}{|c|}{ 95\% Confidence Interval } & \multirow{2}{*}{$\begin{array}{c}\text { Partial Eta } \\
\text { Squared }\end{array}$} \\
\hline & & & & & Lower Bound & Upper Bound & \\
\hline Intercept & 16.866 & 19.079 & .884 & .379 & -21.056 & 54.788 & .009 \\
\hline$[$ Season=1] & .620 & .140 & 4.419 & .000 & .341 & .899 & .183 \\
\hline [Season=2] & .009 & .063 & .141 & .888 & -.116 & .133 & .000 \\
\hline [Season $=3$ ] & -.108 & .059 & -1.820 & .072 & -.226 & .010 & .037 \\
\hline [Season=4] & $0^{\mathrm{a}}$ & & & & & & \\
\hline [Major hooks=7 nos] & .074 & .069 & 1.060 & .292 & -.064 & 211 & .013 \\
\hline [Major hooks $=6$ nos] & $0^{\mathrm{a}}$ & & & & & & \\
\hline$[$ Year=1] & -.296 & .059 & -4.997 & .000 & -.414 & -.178 & .223 \\
\hline [Year=2] & -.319 & .059 & -5.384 & .000 & -.437 & -.201 & .250 \\
\hline [Year=3] & -.153 & .059 & -2.577 & .012 & -.271 & -.035 & .071 \\
\hline$[$ Year $=4]$ & -.052 & .059 & -.883 & .380 & -.170 & .065 & .009 \\
\hline [Year=5] & $0^{\mathrm{a}}$ & & & & & & \\
\hline Latitude & .037 & .117 & .318 & .751 & -.195 & .269 & .001 \\
\hline Longitude & -.151 & .240 & -.627 & .533 & -.628 & .327 & .004 \\
\hline Depth & -.006 & .007 & -.778 & .439 & -.020 & .009 & .007 \\
\hline Distance & .005 & .006 & .927 & .357 & -.006 & .017 & .010 \\
\hline
\end{tabular}


Anuja A. and Yadav V.K. / J. Appl. \& Nat. Sci. 10 (2): 648 - 654 (2018)

Table 5. Generalized linear model (GLMs) indicating relationship of CPUE with independent variables.

\begin{tabular}{lllllll}
\hline Components & \multicolumn{3}{l}{$\begin{array}{l}\text { Normal distribution/ identity } \\
\text { link function }\end{array}$} & \multicolumn{3}{l}{$\begin{array}{l}\text { Gamma distribution/ log link } \\
\text { function }\end{array}$} \\
\cline { 2 - 8 } & Value & df & Value /df & Value & Df & Value /df \\
\hline Deviance & 3.056 & 87 & .035 & .105 & 87 & .001 \\
Scaled Deviance & 100.000 & 87 & & 100.017 & 87 & \\
Pearson Chi-Square & 3.056 & 87 & .035 & .105 & 87 & .001 \\
Scaled Pearson Chi-Square & 100.000 & 87 & & 100.425 & 87 & \\
Log Likelihood & 32.510 & & & 32.880 & & \\
Akaike's Information Criterion (AIC) & -37.021 & & & -37.759 & & \\
Finite Sample Corrected AIC (AICC) & -32.080 & & & -32.818 & \\
Bayesian Information Criterion (BIC) & -.548 & & & -1.287 & \\
Consistent AIC (CAIC) & 13.45 & & & 12.713 &
\end{tabular}

Dependent Variable: $\log _{\text {CPUE }}$

Model: (Intercept), year, season, major hooks, latitude, longitude, depth, distance

Table 6. Factors influencing CPUE in normal and gamma distribution.

\begin{tabular}{lllllll}
\hline Source & Type III (Normal) & & & Type III (Gamma) & & Sig. \\
\cline { 2 - 7 } & Wald Chi-Square & df & Sig. & Wald Chi -Square & 1 & .209 \\
(Intercept) & .897 & 1 & .343 & 1.582 & 4 & .000 \\
Year & 53.022 & 4 & .000 & 55.384 & 3 & .000 \\
Season & 29.470 & 3 & .000 & 28.224 & 1 & .233 \\
Major hooks & 1.291 & 1 & .256 & 1.420 & 1 & .810 \\
Latitude & .117 & 1 & .733 & .058 & 1 & .441 \\
Longitude & .451 & 1 & .502 & .595 & 1 & .407 \\
Depth & .696 & 1 & .404 & .686 & 1 & .342
\end{tabular}

Dependent Variable: $\log _{\text {_ CPUE }}$

Model: (Intercept), year, season, major hooks, latitude, longitude, depth, distance

Thus this division of seasons according to the targeted species of the season and their practice of use of hook and lines clearly indicates a conscious effort at sustainable fisheries in the region.

Fig 2. gives the graphical representation of fish landings, effort and CPUE in Kombuthurai from 2009-2013. It can be seen that when effort decreases fish landings are increases. It may be attributed to new hooks, time, fishing grounds and observation of availability of fishes.

Fig 3 indicates the relationship of CPUE against

Table 7. Hosmer and Lemeshow statistic (Tests of model fit).

\begin{tabular}{llll}
\hline Step & Chi-square & Df & Sig. \\
\hline 1 & 5.042 & 8 & .753 \\
\hline
\end{tabular}

Table 8. Model summary of binary logistic regression.

\begin{tabular}{cccc}
\hline Step & $\begin{array}{c}\mathbf{- 2} \text { Log like- Cox and Snell R Nagelkerke } \mathbf{R} \\
\text { lihood }\end{array}$ & $\begin{array}{c}\text { Square } \\
\text { Square }\end{array}$ \\
\hline 1 & $47.950^{\mathrm{a}}$ & .539 & .754 \\
\hline
\end{tabular}

Table 9. Classification table under binary logistic regression.

\begin{tabular}{|c|c|c|c|c|}
\hline \multirow{3}{*}{ Observed } & & \multicolumn{3}{|c|}{ Predicted } \\
\hline & & \multicolumn{2}{|c|}{ Abundance } & \multirow{2}{*}{$\begin{array}{l}\text { Percentage } \\
\text { Correct }\end{array}$} \\
\hline & & Low & high & \\
\hline \multirow{2}{*}{ Abundance } & low & 65 & 3 & 95.6 \\
\hline & high & 9 & 23 & 71.9 \\
\hline \multicolumn{4}{|c|}{$\begin{array}{l}\text { Overall Percentage } \\
\text { a. The cut value is } 0.500\end{array}$} & 88.0 \\
\hline
\end{tabular}

seasonal and fishing grounds. In the figure A, B, $C, D, E$ and $F$ are different fishing grounds. It can be seen that in there are hardly any variation in fish landing across year in Kombuthurai in season 2, 3 and 4 across all fishing grounds. All fishing grounds have yielded almost steady landings over season 2, 3 and 4 over years only in season 1 there appears to be a fall in carangids landings in 2010. But in all the other years there is a upward or steady landing in fishing ground $C$ and $D$. The falling carangids landing in 2010 in season 1 in C and $D$ fishing ground may be attributed to drop in effort.

[ ${ }^{1}$ Fishing ground season wise- Season 1 contains

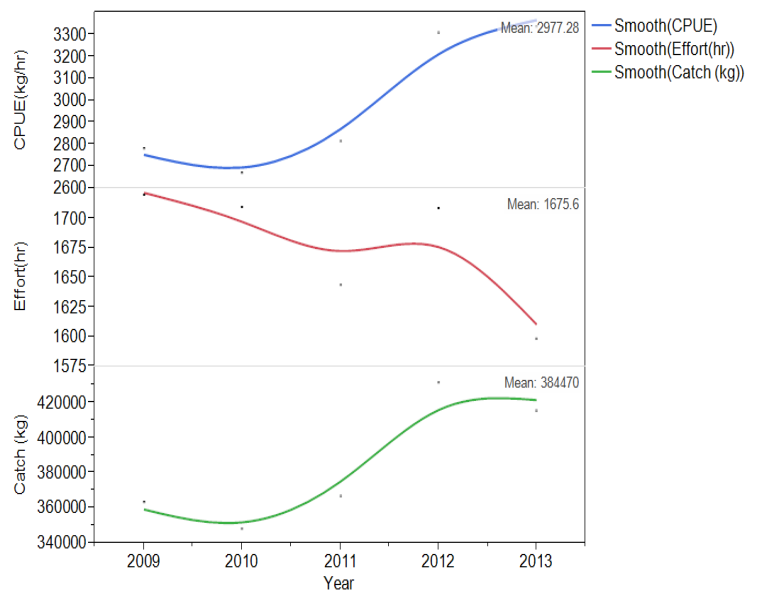

Fig. 2. Fish landings in Kombuthurai (2009-2013). 
Table 10. Parameters estimates in logistic regression.

\begin{tabular}{lllllll}
\hline & B & S.E. & Wald & df & Sig. & Exp(B) \\
\hline Year & & & 3.842 & 4 & .428 & \\
Year(1) & -1.491 & 1.322 & 1.272 & 1 & .259 & .225 \\
Year(2) & -1.491 & 1.322 & 1.272 & 1 & .259 & .225 \\
Year(3) & .501 & 1.007 & .247 & 1 & .619 & 1.650 \\
Year(4) & .000 & 1.039 & .000 & 1 & 1.000 & 1.000 \\
Latitude & -27.198 & 11.964 & 5.168 & 1 & .023 & .000 \\
Longitude & -13.313 & 6.951 & 3.669 & 1 & .055 & .000 \\
Depth & .597 & .295 & 4.099 & 1 & .043 & 1.816 \\
Distance & -.924 & .440 & 4.402 & 1 & .036 & .397 \\
Season & & & 2.330 & 3 & .507 & .995 \\
Season(1) & 42.582 & 7242.221 & .000 & 1 & .659 & .532 \\
Season(2) & -.631 & 1.430 & .195 & 1 & .152 & .085 \\
Season(3) & -2.468 & 1.722 & 2.055 & 1 & .937 & .920 \\
Major hooks(1) & -.084 & 1.060 & .006 & 1 & .036 &. \\
Constant & 1281.391 & 609.930 & 4.414 & 1 &.
\end{tabular}

The model explained $75.4 \%$ (Nagelkerke $\mathrm{R}^{2}$ ) of the variance in high abundance and correctly classified $88 \%$ of cases.

4 fishing ground namely $A=39$ Nautical mile $(\mathrm{Nm})$ par, $\mathrm{B}=43 \mathrm{Nm}$ par, $\mathrm{C}=5$ th par and $\mathrm{D}=35$ $\mathrm{Nm}$ par. Season 2 contains 5 fishing grounds namely $A=$ Seela par, $B=$ Valayappu par, $C=$ Vathai par, $D=$ Oola par and $E=$ Osathi par. Season 3 contains 5 fishing grounds namely $A=$ Osathi, $B=$ Karuval, $C=$ Periyathoppu, $D=$ Kandeduthan par and $E=$ Keelipar. Season 4 contains 6 fishing grounds namely $A=$ Klathi par 1 , B= Punnakayal madai, $C=$ Semmenthalai par, $D=$ Manapadu mannu par, $E=$ Klathi par 2 and $F=14$ pagam par.]

Fig 4 gives the relationship of fish landings by use of major hooks and lines during 2009 to 2013. There are different types of hooks which are used in hook and line fishery. Hooks are classified according to numbers indicating their size and strength. For example hooks no 6 and 7 are used for carangids and seer fishing respectively. The figure indicates that across year carangids fishery with hook no 6 as yielded maximum catch. Hook no 7 yielded the next highest catch for seer fishery. It can be noted that hook no 4 which is the

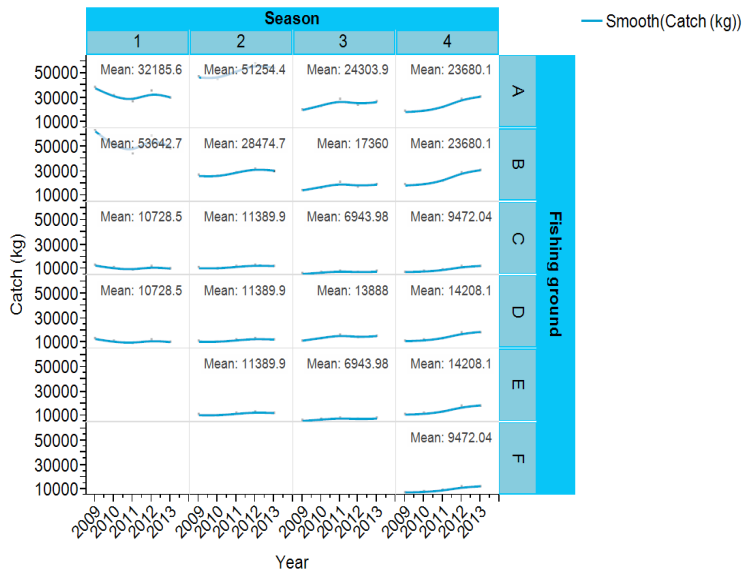

Fig. 3. Seasonal and fishing grounds landings and CPUE (2009-2013). strongest hooks was used for tuna fishery exclusively. It may also be noted that tuna is not a seriously targeted species.

Fig 5 gives the relationship between CPUE and major hooks in Kombuthurai. Similar to the earlier figure it can be seen that CPUE is highest in respect of hooks number 6 used for carangids fishery followed by hook no 7 for seer fishery across years.

Catch - effort relationship (2009-2013) by using general linear models (GLM): The following analysis gives the overall relationship of CPUE with the independent variables considered. Table 2 indicates the error variances with respect to CPUE, are equal across the groups, and the GLM modelwas appeared to be adequately fit to the data.

Table 3 gives the relationship between CPUE and the sources of variance. It was seen from the table that season has a significant and positive relationship with CPUE. In addition to season, year (time variable) also have a significant and positive relationship with CPUE. Overall the independent vari-

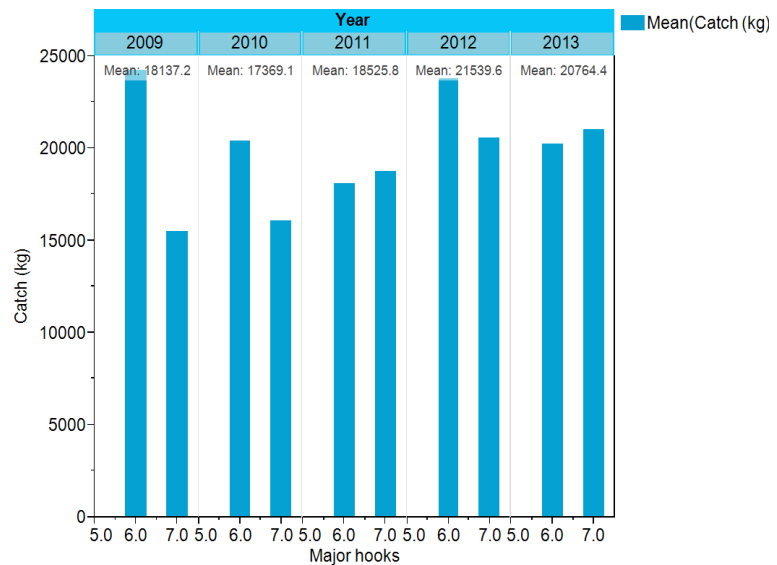

Fig. 4. Relationship of catch vs major hooks in Kombuthurai (2009-2013). 
Anuja A. and Yadav V.K. / J. Appl. \& Nat. Sci. 10 (2): 648 - 654 (2018)

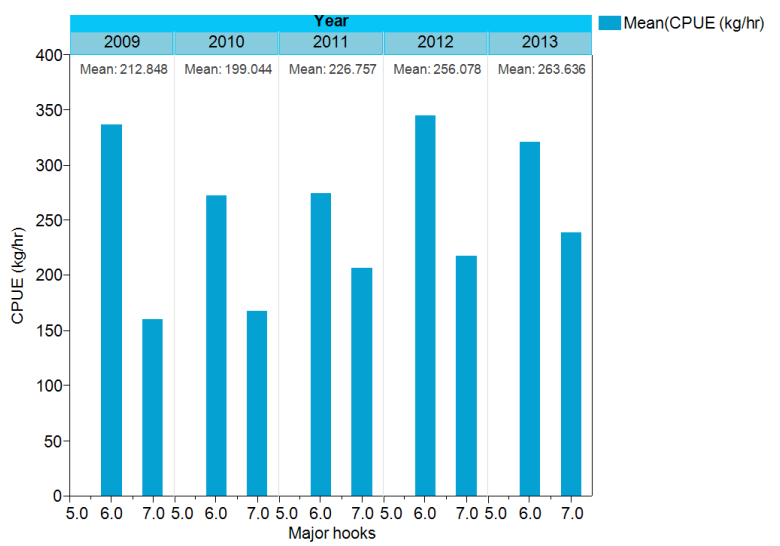

Fig. 5. Relationship of CPUE vs major hooks in Kombuthurai (2009-2013).

able of this model explains as much as $72.40 \%$ of the changes in the dependent variable.

Table 4 gives the relationship between CPUE and various mentioned explanatory variables. The result indicates that keeping season 4 as a reference year, season 1 was emerged significant, contributing as much as $18.30 \%$ change in CPUE and also that year (time variable), year 5 as a reference year, year 1, 2 and 3 were emerged significant, contributing $22.30 \%, 25 \%$ and $0.7 \%$ respectively change in CPUE.

In the above analysis of the influence of various variables on CPUE across the year, It was seen seasons and fishing year have a significant influence on CPUE in the pooled analysis of 20092013. It was also be noted that the GLM model has been a good fit with $\mathrm{R}^{2}$ ranging from $67.60 \%$ to a high of $91.7 \%$

Catch effort relationship by using generalized linear model (GLMs): In the generalized linear model, we adopt link functions that enhance the precision of the model. A generalized linear model is used to fit a normal and gamma distribution for the analysis of scale data. The goodness of fit statistic of GLMs is useful for comparing competing models such as normal distribution with identity link function and a gamma distribution with log link function. Several statistics are calculated to assess goodness of fit of a GLMs. Additionally, the value/df for the deviance and Pearson Chisquare statistics gives corresponding estimates for the scale parameter. Log-likelihood estimates are used in computing the information criteria. Information criteria are used when comparing different models for the same data.

Table 5 gives the deviance of the normal model was estimated to be 3.056 on 87 degrees of freedom and the Akaike Information Criterion (AIC) is -37.021. The deviance of the gamma fit was estimated to be .105 on 87 degrees of freedom and the Akaike Information Criterion (AIC) was 37.759. The model with the smaller AIC is preferred in the GLMs. Here, in this case, gamma fit has less AIC than the normal model.

Table 6 gives the relationship between CPUE and the sources of variation. Type III analysis revealed that 2 out of 7 effects were significant in both normal and gamma with a link function. Test of model effects showed the significant effect only in year and season. It can be seen that in both the distributions only year and season emerge as significant variables.

Catch and effort relationship by using binary logistic regression: Binary Logistic regression is a statistical method for analyzing a dataset in which there are one or more independent variables that determine an outcome. The outcome measured as a dichotomous variable (in which there are only two possible outcomes).

Table 7 gives the Hosmer and Lemeshow statistic that is the goodness of fit statistics. The goodness of fit statistics helps to determine whether the model adequately describes the data. The Hosmer and Lemeshow statistic indicate a poor fit if the significance value is less than 0.05 . Here the model adequately fits the data.

Table 8 gives the variation in the dependent variable explained by the model summary, and this table contains the Cox and Snell $R$ Square and Nagelkerke R Square values, which are both methods of calculating the explained variation. These values are sometimes referred to as pseudo $R 2$ values (and will have lower values than in multiple regressions). Therefore, the explained variation in the dependent variable based on the Cox and Snell R2 and Nagelkerke $R 2$ methods ranges from $53.9 \%$ to $75.4 \%$ respectively. Nagelkerke $R 2$ is a modification of Cox \& Snell R2, the latter of which cannot achieve a value of 1 . For this reason, Nagelkerke $R 2$ value is preferable. The model with the largest $R 2$ statistic is best. Here in this case Nagelkerke $\mathrm{R}$ square model has high $R 2$ than Cox \& Snell R Square.

Binomial logistic regression estimates the probability of an event (in this case, high abundance) occurring. If the estimated probability of the event occurring is greater than or equal to 0.5 (better than even chance), SPSS classifies the event as occurring (e.g., high abundance being present). If the probability is less than 0.5 , SPSS classifies the event as not occurring (e.g., low abundance). It is very common to use binomial logistic regression to predict whether cases can be correctly classified (i.e., predicted) from the independent variables. Therefore, it becomes necessary to have a method to assess the effectiveness of the predicted classification against the actual classification. There are many methods to assess this with their usefulness often depending on the nature of the study conducted. However, all methods revolve around the observed and predicted classifications, which are presented in the 
"Classification Table"(Table 9). It can be seen that $88 \%$ of the variable is correctly classified.

A logistic regression performed to ascertain the effects of year, season, latitude, longitude, depth, distance and major hooks on the likelihood that catch has high abundance. Table 10 gives the output of parameters estimates in logistic regression. Table 10 shows the contribution of each independent variable in the model and its statistical significance. The Wald test ("Wald" column) is used to determine statistical significance for each of the independent variables. The statistical significance of the test is found in the "Sig" column. It can be seen that latitude $(p=0.023)$, longitude $(p=0.055)$, depth $(0.043)$ and distance $(p=0.036)$ added significantly to the model, but the year, season and hooks did not add significantly to the model. The odds of having high abundance ('high' category) is 1.816 and 0.397 times greater for a unit change in depth and distance respectively. There is no change in the odds of having high abundance for a unit change in latitude and longitude.

\section{Conclusion}

Kombuthurai has been described as a fishing village in Thoothukudi district, Tamil Nadu which has gained immense importance by practicing sustainable fishing practices. By using GLM and GLMs analysis, the influence of various variables on CPUE across the year, It was seen that the season and fishing year have a significant influence on CPUE in the pooled analysis of 2009-2013. It may also be noted that the GLM model has been a good fit with $\mathrm{R}^{2}$ ranging from $67.60 \%$ to a high of $91.7 \%$.By using GLMs analysis for normal and gamma distribution with link function, it was noted that the deviance of normal model at 87 degrees of freedom and its AIC along with the deviance of the gamma fit at the same degrees of freedom and its AIC showed that the gamma fit had less AIC than the normal model and therefore the model was a good fit in the GLMs framework be- cause of its smaller AIC. The low and high abundance of CPUE were categorized taking the below and above average CPUE as low and high abundance. A binary logistic regression was performed to ascertain the effects of year, season, latitude, longitude, depth, distance and major hooks on the likelihood that catch has high abundance. The model explained $75.4 \%$ (Nagelkerke $R^{2}$ ) of the variance in high abundance and correctly classified $88 \%$ of cases. The independent variable such as latitude, longitude, depth, and distance added significantly to the model, but the year, season and hooks did not add significantly to the model.

\section{ACKNOWLEDGEMENTS}

This paper forms part of M.F.Sc Dissertation of first author. The authors sincerely thank Dr. W.S. Lakra, Director, CIFE, Mumbai for constant encouragement and for providing necessary facilities for the study.

\section{REFERENCES}

Anuja, A., V.K. Yadav, M. Krishnan and N.R. Kumar (2018). Catch rates and sustainable yield of Hook and Line Fishery -A Case Study of Kombuthurai village of Thoothukudi district of Tamilnadu. Indian Journal of Geo-Marine Science,47(2):489-497

Allen, R. and Punsly, R. (1984). Catch rates as indices of abundance of yellowfin tuna, Thunnusalbacares, in the eastern Pacific Ocean. Bull. InterAmer.Trop.Tuna Comm. 18(4): 301-379.

FAO (2005). The state of world fisheries and aquaculture. Food and Agriculture Organization of the united nations, Rome, pp.3-42

GOT(2012). Government of Tamil Nadu, Department of Economics and Statistics, Statistical Hand Book of Tamil Nadu, 2012. p.41.

Gavaris, S. (1980). Use of a multiplicative model to estimate catch rate and effort from commercial data. Can.J.Fish. Aquati.Sci.37, 2272-2275

Maunder, M.N., and Punt, A.E. (2004). Standardizing catch and effort data: a review of recent approaches, Fisheries Research 70: 141-159

Nelder, J.A., Wedderburn, R.W.M.(1972). Generalised linear models, J. R.Statist. Soc. A 137: 370-384. 